\title{
Camilo José Cela e a crítica acadêmica brasileira: apontamentos sobre a recepção de um ilustre desconhecido*
}

\author{
Camilo José Cela and Brazilian academic critics: \\ notes about the reception of an illustrious unknown \\ Maria Eunice Moreira** \\ Amanda da Silva Oliveira*** \\ Pontifícia Universidade Católica do Rio Grande do Sul - Rio Grande do Sul - Porto Alegre
}

$\diamond$

\begin{abstract}
Resumo: Este artigo enfoca o conjunto de textos publicados no Brasil, no período de 1987 até 2015, sobre o autor espanhol Camilo José Cela e sua produção literária, tomando-se como fonte básica para esse levantamento o banco de dados da CAPES, através do site CNPq/Lattes, acessível pelo endereço http://lattes.cnpq.br/ para a entrada "Camilo José Cela". Busca-se também entender as razões pelas quais o Nobel de Literatura, Camilo José Cela, continua desconhecido pela crítica literária brasileira, em especial, pela crítica acadêmica.

Palavras-chave: Camilo José Cela; Crítica brasileira; Produção acadêmica

Abstract: This article focuses on the set of texts published in Brazil, from 1987 to 2015, on the Spanish author Camilo José Cela and his literary production, using as a basic source for this survey the CAPES database, through CNPq site / Lattes, available in the website http://lattes. cnpq.br/ address for the entry "Camilo José Cela". The aim of this paper is also to understand why the Nobel Prize for Literature, Camilo José Cela, remains unknown by Brazilian literary criticism, particularly by academic criticism.
\end{abstract}

Keywords: Camilo José Cela; Brazilian Criticism; Academics production

"A solidão é o mais alto prêmio que ninguém pode receber."

(Camilo José Cela)

Na década de 1980, enquanto o Brasil ainda vivia sob o regime da ditadura militar e novos ventos bafejavam a Espanha pós-franquista - o General Franco deixara o poder em 1975 - a obra de Camilo José Cela, o futuro Nobel da Literatura, era desconhecida das editoras nacionais e silenciada pela crítica literária, mesmo aquela produzida no âmbito das universidades. Embora sua obra já fosse volumosa e até mesmo um dos seus livros tivesse sido editado na Argentina antes de receber acolhimento na sua terra natal, a obra desse romancista não circulava em língua portuguesa - o primeiro romance traduzido,
Mazurca para dois mortos, somente chegou em solo brasileiro em 1984. Na Espanha, ao contrário, na fase de abertura política pela qual o país atravessava, um livro de Camilo José Cela sintetizava o espírito da época: o romance La colmena. Ler a obra, discutir a questão política por ela suscitada e assistir à película homônima, constituía parte imprescindível de um roteiro cultural com ares de engajamento e abertura. Com o livro e o filme, era possível compreender melhor a Espanha, em um espaço em que as feridas deixadas pela guerra civil ainda estavam abertas.

\footnotetext{
*A expressão "ilustre desconhecido", em relação a Camilo José Cela, foi empregada por Noelci Fagundes da Rocha (Sissa Jacoby), na sua dissertação de Mestrado, intitulada "La família de Pascual Duarte e La colmena. Dois romances de um ilustre desconhecido", apresentada ao PPGL/PUCRS, em 1993. ** Professora titular do Programa de Pós-Graduação em Letras da PUCRS, bolsista CNPq.

***Doutoranda no PPGL/PUCRS (Teoria da Literatura, bolsista CAPES).
} 
A história da edição e publicação dos primeiros livros de Camilo José Cela é significativa do momento político espanhol em que o escritor começou a se forjar. As obras iniciais de Cela foram vetadas na Espanha: $L a$ família de Pascual Duarte foi publicado em Burgos e a segunda edição foi retirada das prateleiras das livrarias espanholas pela censura. Já La colmena foi proibido na Espanha entre 1946 a 1950, e conheceu uma edição argentina, em 1951, pela Editorial Emecê. Mais tarde, quando voltou aos prelos espanhóis, o país de impressão aparecia como o México, quando, na verdade, o livro foi composto em Barcelona.

Camilo José Cela desfrutava, também, de uma posição ambígua no cenário político: o homem Cela, o cidadão Cela, para alguns, era um autor antifranquista; para outros, mantinha contato com o regime fascista; para outros era autor de plágio e ainda havia alguns que diziam ser espião da França. Cela viveu, portanto, sob o signo da insegurança e da desconfiança, provocando a crítica mordaz que atingiu não somente o homem, mas também suas façanhas pessoais e profissionais.

Apesar desses pareceres antagônicos, Cela foi uma espécie de furacão, um ventarrón de libertad (JACOBY, p.69) que agitou o romance espanhol após o marasmo cultural provocado pela guerra civil. Além disso, a figura imponente do escritor, associada à persona que Cela construía, concomitante com sua produção literária, colaborava para essa recepção: as obras, de cunho sociológico, contribuíam para a imagem arrasada de cidadãos também arrasados, que atuavam como abelhas - em torno de um centro ainda desconhecido - ou com insignificante violência - que a miséria e a nova realidade não só sugeriam, mas possibilitavam.

La colmena é um desses exemplos, pois é um livro emblemático e pode ser lido como uma metáfora da nova Espanha. Da mesma forma que em uma colmeia, cujo movimento é intenso, a obra explora uma pluralidade de seres, comportamentos e sentimentos, diversificados e desordenados, como se cada um buscasse seu novo espaço em uma sociedade que tem muito a oferecer, mas que ainda sofre os desgastes de um período dolorido de sua história recente.

La família de Pascual Duarte (1942) é também um livro significativo para o período, pois pode ser lido no contexto desses tempos de incertezas e renovações. Nela, um homem do "pueblo", um certo Pascual, cidadão pacato e insignificante, comete o bárbaro assassinato da mãe, em uma narrativa tensa, dominada pela técnica do narrador. Segundo a crítica, Cela instaurou com esse livro o "tremendismo" em Espanha, explorou a violência e a exclusão sociais - vivida por muitos espanhóis -, o que poderia justificar o atroz delito do campesino Pascual Duarte. Interpretado na conjuntura de um país ainda em convulsão, a morte da mãe simbolicamente significaria a eliminação de outra mãe, a maior - a própria Espanha para que dela nasçam outros filhos, desapegados do tronco que gerou tanta atrocidade. A patologia que constrói a narrativa é, porém, primitiva e primeira - o matricídio fundou a literatura e a sociedade. Por isso, é significativa a declaração de Pascual Duarte: Yo, señor, no soy malo...

Ao contrário da efervescência que os romances do autor provocavam na Espanha, a recepção de Cela inicia-se no Brasil na década de 1980-1990, com pouca intensidade. Para Noelci Fagundes da Rocha (Sissa Jacoby), é interessante o contraste entre a circulação de Cela em seu país de origem e sua entrada em solo tupiniquim: "basta lembrar que a obra-prima de Cela, $L a$ familia de Pascual Duarte só chegou ao leitor brasileiro em 1986, com nada menos que quarenta e quatro anos de atraso, e não merecera, até 1993, qualquer estudo por parte de nossos críticos literários" (p. 12).

\section{Cela e a sua recepção no Brasil}

Ao apresentar a dissertação de Mestrado à PUCRS, em 1994, intitulada "La família de Pascual Duarte e La colmena. Dois romances de um ilustre desconhecido", Sissa Jacoby confirmou que o nome de Camilo José Cela era pouco conhecido pela crítica, mesmo a acadêmica, e que a obra do escritor espanhol não circulava entre os leitores brasileiros, o que a motivou a registrar tal desconhecimento no título do trabalho. O paradoxal qualificativo surgiu de uma ocorrência real por ela vivenciada, ao mencionar o escritor que pretendia abordar em sua pesquisa, em uma conversação acadêmica. A essa observação, seguiu-se uma pergunta que continha, em si, uma sugestão para outro direcionamento à dissertação: por que não estudar alguém mais conhecido em uma monografia do porte de uma dissertação de Mestrado? Para a estudiosa, o quase total desconhecimento da produção de Camilo José Cela, na década de 1990, no Brasil, poderia ser justificada

pela falta de estudos a respeito de seus livros, pela ausência de artigos em jornais e revistas, e, principalmente, pela tardia e escassa tradução de seus romances para a nossa língua - que não excede o número três ${ }^{1}$, embora a produção de Camilo José Cela, abrangendo diversos gêneros e variações dos mesmos, beire os cem títulos (JACOBY, 1993, p. 8).

Essa situação contrapunha-se à verificada no continente norte-americano, onde Cela aparecia em situação totalmente oposta: era o autor com "mais teses

\footnotetext{
Os dados referem-se à época da elaboração da dissertação de Mestrado, em 1993
} 
de doutoramento (...) dedicadas nos Estados Unidos, passada a febre de Miguel de Unamuno e García Lorca" (JACOBY, 1993, p.9) e o livro A família de Pascual Duarte era o romance mais traduzido depois do célebre El ingenioso Don Quijote de la Mancha. Certamente contribuía também para a restrita circulação da obra de Dom Camilo, no mercado brasileiro, a dificuldade de leitura de seus textos. Como assinala Sissa Jacoby, señor de la lengua, inventor de palabras, creador de lenguaje, Cela orquestrou todos os registros do idioma (JACOBY, p.69), o que o tornou um escritor "difícil de ler". Dos textos clássicos à linguagem coloquial, de recursos literários provenientes do abrangente elenco de leituras que o moldara à transgressão de gêneros e formas, criou uma língua peculiar e uma literatura original, considerada, às vezes, hermética, embora moderna e vanguardista:

\begin{abstract}
Desde a crueza do relato autobiográfico do camponês de La família de Pascual Duarte, seu universo ficcional experimentou os mais variados caminhos, trilhando a vanguarda na maioria das vezes e servindo de guia a muitos escritores jovens. A busca constante pelo novo e o repúdio a uma fórmula pronta de fazer literatura lhe garantiram os apodos merecidos, ainda que paradoxais, vanguardista e clássico vivo. Comentários como: es hoy uno de nuestros novelistas más vanguardistas ou es mucho más moderno, o sea contemporáneo, que la mayoría de los escritores de la edad que sean ou, ainda, es un escritor rebelde: mucho más moderno que esos jovencitos promovidos por las empresas editoras ${ }^{2}$, constituem moeda comum quando o assunto é don Camilo. Moderno e vanguardista, ainda que já um clássico (2009, p. 61).
\end{abstract}

Em que pesem essas questões, Cela foi pouco lido e menos ainda traduzido no Brasil. Essa situação perdurou e perdura até hoje, pois mesmo a vinda do laureado escritor a Porto Alegre, em 1995, para participar da tradicional Feira do Livro, evento que se realiza anualmente na capital do Rio Grande do Sul, em todos os meses de novembro, não alterou significativamente sua recepção em terras brasileiras. Ao chegar ao país americano, pela primeira vez, acompanhado de sua esposa, Marina Castaño, Dom Camilo, como costumava ser chamado, constatou que até, aquele momento, do total de quase cem títulos que compunham a obra que vinha escrevendo desde a década de quarenta do século XX, apenas cinco livros mereceram tradução para a língua portuguesa, por editoras brasileiras, com largos espaços de tempo entre uma edição e outra: Mazurca para dois mortos foi lançado em 1984, pela Difel, e A família de Pascual Duarte somente chegou ao conhecimento do leitor brasileiro em 1986, pela mesma editora, ou seja, quarenta e quatro anos após seu lançamento. Depois dessas duas obras, foram necessários mais seis anos para as traduções seguintes, todas agora sob a responsabilidade da Bertrand Brasil: A colmeia, em 1992, O assassinato do perdedor, em 1995 e ainda nesse ano viria a público Tateios, saracoteios e outros meneios. Considerando o sucesso dos livros de Cela na Espanha e nos Estados Unidos - apenas para citar um país além do seu natal - o Brasil conheceu as obras do Nobel de Literatura com muito atraso, pois o prêmio da Academia Sueca lhe foi outorgado em 1989.

Antes do recebimento do Nobel, a crítica sobre a obra de Cela resume-se a esparsos artigos publicados em jornais brasileiros: em 1987, Ester Abreu Vieira de Oliveira escreveu sobre "A arte verbal de Cela", no jornal A Gazeta, de Vitória, ES. Em 1989, Augusto Massi, então pós-graduado em Literatura Espanhola pela USP, publicou um pequeno texto na Folha de São Paulo, chamando a atenção para a personalidade do autor espanhol, sempre envolto em polêmica, "escandaloso e controvertido em suas participações na vida cultural do país"3 e autor de si mesmo, ou seja, "cujo principal papel é sempre representar Camilo José Cela"4. Nesse mesmo ano, ensejado pelo Nobel, Marinalva Freire da Silva escreveu um artigo sobre o prêmio recebido por Cela, em Linguagem Viva, de São Paulo. Dois anos depois, em um Congresso de Professores de Espanhol, Maria Thereza da Silva Venancio apresentou La família de Pascual Duarte como tema de uma comunicação.

Afora esses trabalhos, duas resenhas, de 1993, ambas de autoria de Amaya Obata M. de A. Prado, enfocaram a obra La colmena, resenha que ocupou espaço no jornal El Camino, publicação anual da área de Espanhol da UNESP/Assis e foi igualmente divulgada pela Consejería de Educación de la Embajada de España, em São Paulo. À exceção de três comunicações sobre a obra de Dom Camilo em eventos no Sul do País, a crítica ficou circunscrita ao eixo cultural Rio de Janeiro-São Paulo, onde estavam localizados os cursos de pós-graduação com especialização em Literatura Espanhola, espaços de discussão provável da produção celiana.

Em 1993, Sissa Jacoby apresentou a dissertação de Mestrado no PPGL/PUCRS, enfocando enfoca os dois livros mais conhecidos de Cela - A família de Pascual Duarte e A colmeia - com o objetivo de "estabelecer não só uma relação entre esses dois romances, como também uma relação entre a realidade ficcional e a

\footnotetext{
2 Segundo Sissa Jacoby, "as citações, respectivamente, correspondem a Luis Ventoso, em El gigante y los enanos. Diario 16, Madrid, 29 abr. 1999, p. 12; Suso de Toro em Tener madera, Diario 16, Madrid, 29 abr. 1999, p. 12; Francisco García Marquita, em Madera de Nobel, Madrid, octubre 1999, n. 106, p. 20".

3 MASSI, Augusto. Eterna renovação do escândalo. O Estado de São Paulo, São Paulo, 20 out. 1989. Disponível em: <http://acervo.estadao. com.br/publicados/1989/10/20/g/19891020-35176-nac-0043cd2-1-nothehkpas.jpg $>$.

4 Ibidem.
} 
realidade histórica na qual se inscrevem" (1994, p. 33), como esclarece em A ficção de Camilo José Cela: além do bem e do mal, título que a dissertação de Mestrado tomou quando foi transformada em livro e publicada pela Editora da Universidade de São Carlos, SP, em parceria com a editora Mercado Aberto, de Porto Alegre, RS, em 1994. Portanto, até a vinda de Camilo José Cela ao Brasil, tanto a dissertação, agora transformada em livro, constituíam as fontes de maior envergadura e profundidade para conhecimento da obra do Nobel espanhol, no Brasil. Por outro lado, o privilégio conhecido pela crítica aos dois livros de Cela, propiciou a constante retomada desses títulos, nos anos posteriores junto à comunidade acadêmica brasileira.

\section{A passagem de Cela pelo Brasil (e por Porto Alegre)}

Em 1995, após gestões que se desenvolveram ao longo de quase dois anos, despendidas inicialmente por Roque Jacoby, então Presidente da Câmara RioGrandense do Livro, e, depois, por Julio Zanotta, que o substituiu na Presidência dessa agremiação, o Nobel de Literatura Camilo José Cela chegou ao Brasil, mais especificamente a Porto Alegre e à Feira do Livro. As tratativas para sua vinda foram sendo tecidas aos poucos e para isso contribuíram vários fatores que, associados, resultaram satisfatoriamente. Primeiramente, um estudo de maior porte sobre a obra do escritor espanhol, em recinto acadêmico, afiançou, de certo modo, o reconhecimento da importância do escritor e colaborou para a divulgação de seus livros. Posteriormente, quando a agora doutoranda foi para a Espanha para estudar a obra celiana, conheceu o famoso escritor formulou o convite para a viagem a Porto Alegre. Nesse momento, a Feira do Livro buscava maior internacionalização e a vinda de um autor laureado com o Nobel de Literatura era uma medida que poderia concretizar a intenção dos dirigentes da Feira do Livro. À iniciativa da Câmara, juntava-se o interesse do Consulado da Espanha, em Porto Alegre, liderado pelo então Cônsul Iñigo de Palacio-España, personalidade muito atuante no meio cultural da cidade e conhecedor da literatura de sua terra. A conjunção de interesses e esforços, e a aceitação do convite por parte do homenageado, resultaram positivas e ficou acertada a vinda de Dom Camilo para novembro de 1995, o que correu nos dias 7 e 8 de novembro.

Entre as inúmeras homenagens de que foi alvo pelas autoridades locais e pela atenção da mídia cultural rio-grandense, no dia 7 de novembro de 1995, Camilo José Cela recebeu, na PUCRS, em cerimônia para a qual afluíram autoridades, convidados e comunidade acadêmica, o mais alto galardão concedido pela Universidade a personalidades de destaque: o título de Doutor
Honoris Causa. Os registros dessa homenagem estão compilados em uma publicação especial, bilíngue, lançada pela Edipucrs, cujo título é Viagem ao Brasil: o Nobel Camilo José Cela na PUCRS, publicada quatorze anos após a visita de Camilo José Cela a Porto Alegre. A data de lançamento encontra forte justificativa: em 2009, comemoravam-se cinquenta anos da publicação de La rosa, quarenta anos de San Camilo, 1936, vinte anos da outorga do Nobel e dez anos de Madera de boj, além dos quinze anos da vinda de Cela a Porto Alegre. O objetivo da publicação foi explicitado por Sissa Jacoby, quando escreveu:

reavivar, através da memória escrita, a passagem de uma das figuras mais importantes da literatura universal do século XX, por esta Universidade, marcando sua presença física nos bancos da PUCRS, em dois dias do mês de novembro de 1995 (JACOBY, 2009, p. 11).

Viagem ao Brasil é uma viagem no tempo, mas é também uma viagem a um território específico: a Pontifícia Universidade Católica do Rio Grande do Sul, pois nela recupera-se o percurso de Camilo José Cela na instiuição, as homenagens de que foi alvo, pela concessão do título de Doutor Honoris Causa, e a realização do Seminário sobre sua obra, que ocorreu na Universidade. A publicação reúne os pronunciamentos do Ir. Dionísio Fuertes Alvarez, então diretor do Instituto de Cultura Hispânica da PUCRS, e do Ir. Elvo Clemente, intelectual de destaque na Universidade, e registra a experiência vivida por todos naquela semana, que contou com a figura ínsigne do Nobel Camilo José Cela, no campus universitário da PUCRS. Os depoimentos oferecem, também, a visão peculiar de cada leitor na sua experiência com a obra de Cela, destacando aspectos singulares na visão de cada especialista. Para o Ir. Dionísio Fuertes Alvarez, Cela "irrompeu efetivamente com enorme alvoroço em todos os círculos literários, espanhóis primeiro, e mundiais depois, quando apareceu nas bancas das livrarias em 1942 o seu primeiro romance com o título de A família de Pascual Duarte" (2009, p. 21). O romance, que contrastava com a baixa auto-estima da ficção e da realidade da Espanha da época, causou escândalo e teve duras críticas. Para esse estudioso, conterrâneo do escritor, o texto de Cela "como num gesto taumatúrgico, chamou à vida, fez ressuscitar, de fato, a ficção espanhola que parecia jazer inerte, morta e enterrada, ao terminar a hecatombe da grande revolução" (2009, p. 21).

Já o Ir. Elvo Clemente afirma que, de suas experiências literárias, Nuevas escenas matritenses parece opor-se a tudo que ensinou com texto literário. No entanto, sua avaliação é refeita, pois "cada cena é um aspecto, uma nesga de Madrid que perpassa no texto do narrador arguto e fiel aos costumes e à fala dos personagens" (2009, p. 39) . E complementa: "o retrato do ambiente físico da rua, 
da praça ou da casa se completa com o retrato físico e moral do personagem que por sua vez busca no estilo dos diálogos ou dos monólogos o retrato da rua, do homem, servo de seus misteres" (2009, p. 41).

Ao tomar a palavra e agradecer ao público as deferências a ele concedidas, Dom Camilo tem oportunidade de apresentar suas ideias sobre literatura, cultura e vida. Como homem de letras e intelectual que "vive" a experiência de ser-no mundo e, em especial, no mundo da literatura, Cela assim se pronuncia:

Llevo ya muchos años peleándome con este fiero dragón de la letra impresa, el pensamiento y el buen orden de las conductas tanto individuales como colectivas $\mathrm{y}$, navegando ya las últimas singladuras de mi travesía, asisto, entre atónito e sobrecogido, al amargo espectáculo de esta lucha por el pan ácimo de la supervivencia en la que ni entro ni salgo porque para mí carece de todo interés: les hablo a ustedes no de la literatura, la cultura y la política, claro está, sino que de la revuelta vida literaria y de la turbia vida cultural del mundo entero. Pero que nadie se impaciente porque la literatura, la cultura y la política, al final, triunfan y sobreviven porque son la vida misma y contra la vida no puede ni la muerte, aunque suela pensarse lo contrario (p.26).

As palavras de Cela remetem à afirmação que dele fez seu discípulo e amigo, Francisco Umbral. Para esse conhecedor da personalidade e da produção de Dom Camilo, Cela comunicava literatura, pensava sobre literatura e expressava seu pensamento com imagens literárias, da mesma maneira que um pescador vive a experiência da pesca. Não há como separar o literato do homem, não há como dissociar o escritor da literatura. Para Umbral, Cela sempre concedia um matiz literário à experiência mundana que, não sendo literatura, era entendida e vivida como tal.

Cela entendia os autores como "lobos errabundos", como "navegantes" cujo prêmio é a "soledad": "la soledad es el más alto premio que nadie puede recibir" (2009, p.28). O escritor, que leva "el pecado en la penitencia y al revés: el premio en la soledad, la companía de los tristes, como quiso llamarle Miguel de Cervantes" (2009, p. 28), destaca três elementos essenciais para a compreensão de sua conduta: a independência, que "debe abocarnos y mantenernos en la desobediencia y aun en el desprecio" (2009, p. 28$)$, a liberdade, que defende "muy serenamente y sin apasionamiento alguno, sin demasiada fe en el hombre e incluso sin una excesiva convicción" (2009, p. 30) e a verdade, que "habita en lo más íntimo del hombre, decía San Agustín, y el temor a la verdad, para Amiel, es lo que rige el mundo: a golpes de odio, podríamos suponer ahora, parafraseando Ausonio, el romano bordolés" (2009, p. 30).
As palavras revelam muito do homem que produz os escritos que temos em mãos, tão bem representados com La colmena e La familia de Pascual Duarte. Se "quando se confunde el adjectivo con el substantivo, la apariencia con la esencia, el estar con el ser, se puede fingir el triunfo, sí, pero jamás se vence" $(2009$, p. 30$)$, parece que Dom Camilo segue se referindo a cada um de nós, seres humanos, que habitamos um espaço que sequer sabemos como, de fato, se constitui e se delimita. Por vezes, seu discurso sugere que, tal qual na Espanha, os brasileiros também encontram-se às voltas de uma colmeia, como animais, numa constituição social que oprime e que incentiva o pior de nós todos. Lembra, com ironia, que "dentro de cien años, todos calvos, dice el refrán español i es cierto, pero nadie olvide que unas calaveras brillarán con más dignidad que otras" $(2009$, p. 30). Para Cela, "en la medida en que somos capaces de identificar los fenómenos de la conciencia, (...) pensar resulta, para el hombre, pensar en ser libre" (2009: , p. 32). E conclui:

Y nada más. Anacarsis asegura que los inteligentes deliberan y los necios deciden. Probemos en las Universidades, en las ágoras del pensamiento, a seguir deliberando y aprendiendo y dejemos la necedad para quienes no pueden substraer a la inercia del monótono hábito ni aciertan a huir de la contemplación de los siempre repetidos vaivenes del péndulo de la historia (2009, p. 34).

O compromisso do autor para "com a realidade individual, social e histórica encontra seu momento crítico exatamente no acontecimento-chave da história da Espanha do século XX: a Guerra Civil de 1936-1939” (2009, p. 63). Apesar da defesa de ser o mais contido em relação aos "escritores que participaram da contenda" (JACOBY, 2009, p. 63), "sua obra está impregnada por essa necessidade de reflexão, ora irônica ora amargurada, sobre a insânia da guerra, sempre vinculada à violência e à morte, como acontece em La familia de Pascual Duarte (1942), La colmena (1951), Mazurca para dos muertos (1983). Por isso, como disse Francisco Umbral, Cela se distingue como escritor, ao contrário daqueles que não o são, porque "Cela era literatura" 5 em todas as suas ações e pensamentos:

En qualquier caso, Cela comunicaba literatura, estaba en el interior de la literatura, su lenguaje era naturalmente literario, briosamente literario, y lo que he llamado el clima Cela era vivir dentro de la literatura con la misma naturalidad y fragancia que un pescadero vive en su pescadería 6 .

\footnotetext{
UMBRAL, Francisco. Cela: um cadáver exquisito. Barcelona: Planeta, 2002. p. 71

6 Ibidem.
} 
A década de 1990 fecharia com a conclusão do curso de Doutorado de Sissa Jacoby e a apresentação da tese intitulada "Autobiografia e ficção: memórias, fingimentos e verdades em Camilo José Cela". Nesse novo estudo sobre o autor e sua produção memorialística, a autora discute ficção e autobiografia, através do confronto entre La rosa (1959; 2001) e Memorias, entendimientos y voluntades (1993) com seu romance mais polêmico: San Camilo 1936 (1969), um longo monólogo contra a insânia da Guerra Civil Espanhola.

\section{E o que se tem falado sobre Cela?}

Em 1995, Camilo José Cela recebeu o Prêmio Cervantes, reputado reconhecimento internacional - uma espécie de Nobel para escritores de língua espanhola. Cela firma, mais uma vez, sua posição de destaque na comunidade literária internacional, agregando os dois prêmios mais famosos no campo da literatura: o Nobel e o Cervantes. Talvez motivada por essa posição singular entre os escritores de língua espanhola, a obra do romancista foi objeto de estudo de dois artigos de autoria de Bella Josef, prestigiada crítica literária e professora universitária brasileira, cujo campo de estudo centralizava-se em autores e obras da América Latina, em Língua Espanhola. Em ambos os artigos que escreveu sobre o Nobel, Bella Josef destaca a posição de vanguarda de Cela: em "Camilo José Cela (um renovador do romance espanhol do pósguerra)" ", fica evidente a importância do romancista na renovação do cenário literário, após a guerra civil. Já no outro texto, publicado no Jornal do Brasil, do Rio de Janeiro, a mesma autora destaca a "Nova dimensão do cotidiano (o Nobel Camilo José Cela choca por seu estilo denso e fragmentado e experimental" , reafirmando o caráter inovador da prosa celiana, na contemporaneidade espanhola.

Apesar, porém, da premiação e do novo destaque concedido ao escritor, a crítica acadêmica brasileira aguardaria até a próxima década, ou seja, a partir de 2000, para dispender maior atenção à produção de Dom Camilo, motivada, talvez, pelos novos lançamentos de suas obras, pelas exigências de publicação, acentuadas no âmbito dos programas de pós-graduação ou acionada pela morte do romancista, ocorrida em 2002. Tomando-se por referência a plataforma Lattes/CNPq, que registra a produção intelectual de professores e docentes vinculados às instituições universitárias brasileiras, é possível observar uma expansão no material crítico sobre o autor e

\footnotetext{
JOSEF, Bella. Camilo José Cela (um renovador do romance espanhol do pós-guerra). Rioartes, Rio de Janeiro, n. 19, p. 3-4, 1995

8 JOSEF, Bella. Nova dimensão do cotidiano (o Nobel espanhol Camilo José Cela choca por seu estilo denso, fragmentado e experimental). Jornal do Brasil, Rio de Janeiro, Ideias/Livros, 4 nov. 1995. p. 5.
}

sua obra. Consideram-se, para esse levantamento, os itens que expressam a produção gerada no espaço universitário: teses de Doutorado, dissertações de Mestrado, Trabalhos de Conclusão de Curso (TCC), na graduação, de um lado, e a produção bibliográfica e técnica de outro, representada por edição de livros, publicação de artigos e apresentações de trabalhos em eventos nacionais e internacionais.

No levantamento procedido, é possível constatar que no período de 2000 a 2015, a produção de Camilo José Cela, com diferentes abordagens e finalidades também distintas, mereceu a atenção da crítica acadêmica com pelo menos um registro por ano. Dos quinze estudos incluídos no item "Apresentação de trabalho", sete enfocam a novela do camponês rústico, cinco referemse à metáfora da "colmena" e três voltam-se para o $L a$ família..., enfocando o universo da sociedade espanhola, presentes nos dois romances. Ao lado dessas obras, incluem-se duas outras que, embora objeto de crítica esparsa, no Brasil, foram motivo de consideração: Madeira de lei e $O$ assassinato do perdedor. Especialmente essa última, discutida no âmbito da Faculdade de Direito da PUCRS, teve repercussão através do evento "Direito e Literatura", promovido pela Faculdade de Direito e pela Faculdade de Letras, dessa instituição, do que originou a maior divulgação da obra em um programa de televisão, em canal de Porto Alegre. Nesse caso, o tema do livro ensejou o conhecimento extramuros da obra, motivado mais pelo caso do tema jurídico - o assassinato - do que pela discussão literária da obra.

É interessante observar, contudo, no conjunto do material crítico da década de 2000, a predominância dos Trabalhos de Conclusão de Curso (TCC) sobre as outras modalidades de produção cientifica. Nesse período, foram apresentados nove TCCs, em diferentes instituições de ensino brasileiras, localizadas nos estados do Ceará, de São Paulo, do Paraná e do Rio Grande do Sul, numa distribuição geográfica que privilegia as regiões Nordeste, Sudeste e Sul. Chama a atenção que as universidades nas quais esses trabalhos foram elaborados ainda mantêm a disciplina Língua/Literatura Espanhola nos currículos escolares ou oferecem Língua Espanhola como eletiva para alunos universitários, o que permite reconhecer que a difusão da obra dos escritores depende, em grande parte, da divulgação dos autores e da produção artística de "ilustres desconhecidos".

No âmbito das dissertações de Mestrado, registra-se apenas o estudo de Frank Nabeta, apresentada também na USP, em 2006, sob o título "O triunfo da inércia poder, violência e alienação em La colmena, de Camilo José Cela". O texto retoma a obra mais conhecida do autor e incide tematicamente sobre as relações de poder que conformam essa narrativa de Cela. É significativo que, na metade da década de 2000 e distantes já quinze 
anos do recebimento do Nobel de Literatura, o acervo da análise crítica continua centralizado em torno da obra $\mathrm{La}$ colmena, sem que outras obras, de teor literário mais forte e tecnicamente superiores, propiciem novas reflexões por parte da crítica.

Em nível de tese de Doutorado, apenas em 2015, ou seja, dezesseis anos depois do trabalho de Sissa Jacoby, foi apresentada nova tese de Doutorado sobre o autor espanhol, no Brasil, escrita por Solange Chagas do Nascimento Munhoz, na USP. Sob o título "Bastidores de papels de Son Armadans: as correspondências de Cela e os exilados. Alberti, Aub, Castro e Emilio Prados", objetiva analisar as cartas de Camilo José Cela a seus amigos exilados, no período entre 1950-1970, contidas no livro Correspondencias con el exilio, publicado em 2009.

Enfim, é possível afirmar que a crítica brasileira, restrita ao ambiente acadêmico, centraliza-se sobre $L a$ colmena e La familia de Pascual Duarte, primeiros livros do autor conhecidos pelos leitores brasileiros. Nas análises desses romances, cristalizam-se certas questões temáticas, sem variação: o espaço múltiplo e disperso da sociedade espanhola, o matricídio perpetrado por Pascual, a relação das obras com o ambiente social e político da Espanha pós-guerra civil. Esses tópicos tendem a se ratificar e imobilizar a avaliação dos dois livros, mas, por outro lado, funcionam com uma espécie de barreira impeditiva para a leitura de outras obras do autor. Junte-se a isso - e talvez pela falta de leitores - a escassa tradução para o Português de um autor considerado "difícil" e teremos um quadro que poderia justificar o reduzido espaço dispensado pela crítica ao Nobel da Literatura, Camilo José Cela, ainda em 2016.

Talvez valham aqui, ao final, as considerações de Francisco Umbral, "discípulo díscolo" de Camilo José Cela sobre a produção de seu amigo e mentor. Se díscolo é aquele que costuma desobedecer e insubordinar-se às normas, às regras, pode-se dizer que cabe a Cela tal adjetivo, pois, revelou, pela ficção, parte das questões que diziam respeito à Espanha que conhecia em profundidade, mas mostrou também o lado mais sombrio dessa sociedade e das personagens que constituíam a "colmeia" desses novos incontidos tempos. Por isso mesmo, "díscolo" e "exquisito" dificultou a compreensão dos críticos que, buscando desvendá-lo e entender sua obra, muitas vezes se sentiram imobilizados pela grandeza de seu poder criador. George Agambem, o teórico da contemporaneidade, cita Michel de Foucault para entender que "as perquirições históricas sobre o passado são apenas a sobra trazida pela sua interrogação teórica do presente" ${ }^{\text {" }}$. Nesse caso, as questões históricas acionadas pela obra de Camilo José Cela remetem às possibilidades de interrogações sugeridas pelo presente, o que depende da capacidade crítica e interpretativa de seus leitores. E Cela parecia prever que essa compreensão chegaria mais tarde. Afinal, a solidão é ainda o mais alto prêmio que ninguém pode receber.

\section{Referências}

AGAMBEN, Giorgio. O que é o contemporâneo? e outros ensaios. Chapecó: Argos, 2009.

JACOBY, Sissa. Autobiografia e ficção: memórias, fingimentos e verdades em Camilo José Cela. 1999. 272fls. Tese (Doutorado em Letras) - Pontifícia Universidade Católica do Rio Grande do Sul, Porto Alegre, 1999.

JACOBY, Sissa. Desconstrução e (re)construção: A família de Pascual Duarte e A Colmeia. Dois romances de um ilustre desconhecido. 1993. 194fls. Dissertação (Mestrado em Letras) - Pontifícia Universidade Católica do Rio Grande do Sul, Porto Alegre, 1993

JACOBY, Sissa. A ficção de Camilo José Cela: além do bem e do mal. Porto Alegre: Mercado Aberto, 1994.

MOREIRA, Maria Eunice; JACOBY, Sissa (Org.). Viagem ao Brasil: o Nobel Camilo José Cela na PUCRS. Porto Alegre: Edipucrs, 2009.

UMBRAL, Francisco. Cela: um cadáver exquisito. Barcelona: Planeta, 2002.

Recebido: $08 / 01 / 2016$

Aprovado: 29/01/2016

Contato:maria.eunice@pucrs.br profamandaoliveira@gmail.com

\footnotetext{
9 AGAMBEN, Giorgio. O que é o contemporâneo? e outros ensaios. Chapecó: Argos, 2009. p. 72.
} 